ECCOMAS

\section{Proceedia}

COMPDYN 2017

6th ECCOMAS Thematic Conference on Computational Methods in Structural Dynamics and Earthquake Engineering

M. Papadrakakis, M. Fragiadakis (eds.) Rhodes Island, Greece, 15-17 June 2017

\title{
NUMERICAL SIMULATION OF THE PERFORMANCE OF A WIND TURBINE TOWER WHEN SUBJECTED TO WIND AND EARTHQUAKE FORCES
}

\author{
G.C. Manos $^{1}$, G. Panagiotou ${ }^{2}$, G. Manolis ${ }^{3}$ \\ ${ }^{1}$ Professor Emeritus, Lab. of Strength of Materials and Structures, Aristotle University \\ e-mail: gcmanos@civil.auth.gr \\ ${ }^{2}$ Civil Engineer, Lab. of Strength of Materials and Structures, Aristotle University \\ e-mail: panageor@civil.auth.gr

\footnotetext{
${ }^{3}$ Professor and Director of the Lab. of Strength of Materials and Structures, Aristotle University
} \\ e-mail: gdm@civil.auth.gr
}

Keywords: Wind turbine, Supporting tower, Numerical Simulation, Dynamic and Earthquake Behaviour, Influence of Soil Deformability.

\begin{abstract}
Wind turbines are renewable energy sources that are continuously increasing in numbers and seize. The main structural part, which is the tall tower and its foundation supporting the turbine, is designed to withstand a variety of load combinations. These include the gravitational forces together with a variety of loads that are transferred from the turbine to the tall supporting tower depending on the wind direction and intensity and on the operative condition of the turbine. Such a wind turbine supporting tower made of steel and being supported on a reinforced concrete $(R / C)$ foundation is studied numerically here. Initially, the Thrust and Torque transmitted from the wind turbine blades to the steel tower are obtained through either a commercial software or a software developed by the authors. Next, the numerical simulation of the steel tower and its $R / C$ foundation is formed, with or without flexible soil conditions, and its dynamic characteristics are presented and discussed. Finally, these numerical models are subjected to specific combinations of gravitational forces and airflow as well as extreme conditions linked with circuit breakdown, restart and an assumed design earthquake for Greece. The obtained results, in terms of stress and deformation of the critical elements of the steel tower and its $R / C$ foundation, are presented and discussed.
\end{abstract}

(C) 2017 The Authors. Published by Eccomas Proceedia.

Peer-review under responsibility of the organizing committee of COMPDYN 2017. doi: $10.7712 / 120117.5417 .16896$ 


\section{INTRODUCTION}

Wind turbines are renewable energy sources that are continuously increasing in numbers and seize (figure 1a). The main structural part, which is the tall tower and its foundation supporting the turbine, is designed to withstand a variety of load combinations [1], [4], [14]. These include the gravitational forces together with a variety of loads that are transferred from the turbine to the tall supporting tower depending on the wind direction and intensity and on the operative condition of the turbine. Wind turbines operate under challenging loading regimes (Burton et al., 2001, [2]) the effects of which could diminish their structural integrity leading to significant remediation costs and the potential for structural damage, which is the focus of the present study. The most stressed parts of the structural system of a wind turbine are the ones of the steel tower near its connection to the concrete foundation as well as the foundation itself (figure 1b) [13]. This is due to the fact that the forces generated for the various extreme loading conditions from the operation of the wind turbine combined with extreme loading conditions from natural hazards (e.g. seismic events for onshore wind turbines) result in a regime of maximum overturning moment, shear force and axial force for this location of a wind turbine. The structural performance could also be susceptible to damage in cases of faulty construction or poor maintenance.

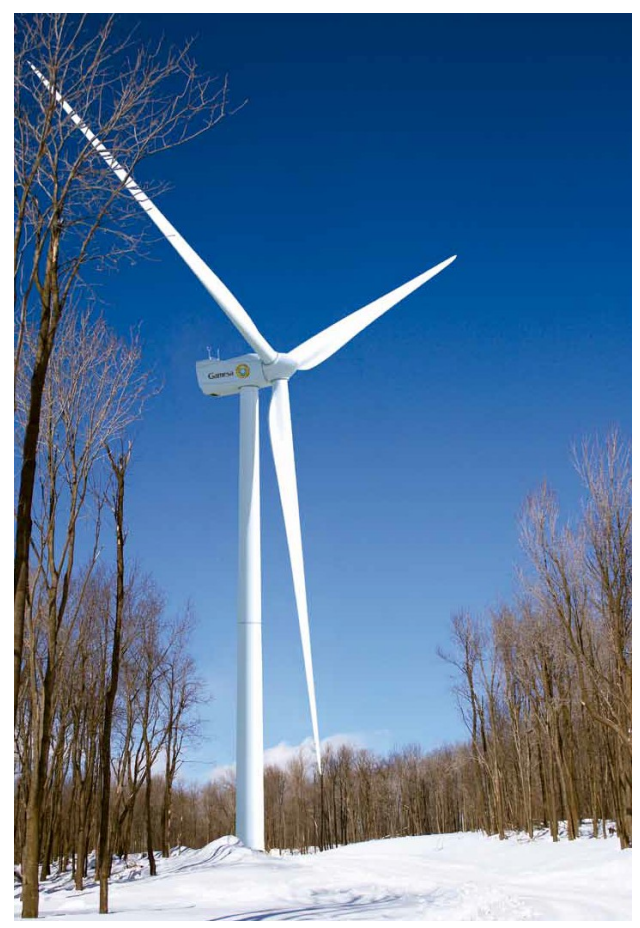

Figure 1a. A wind turbine

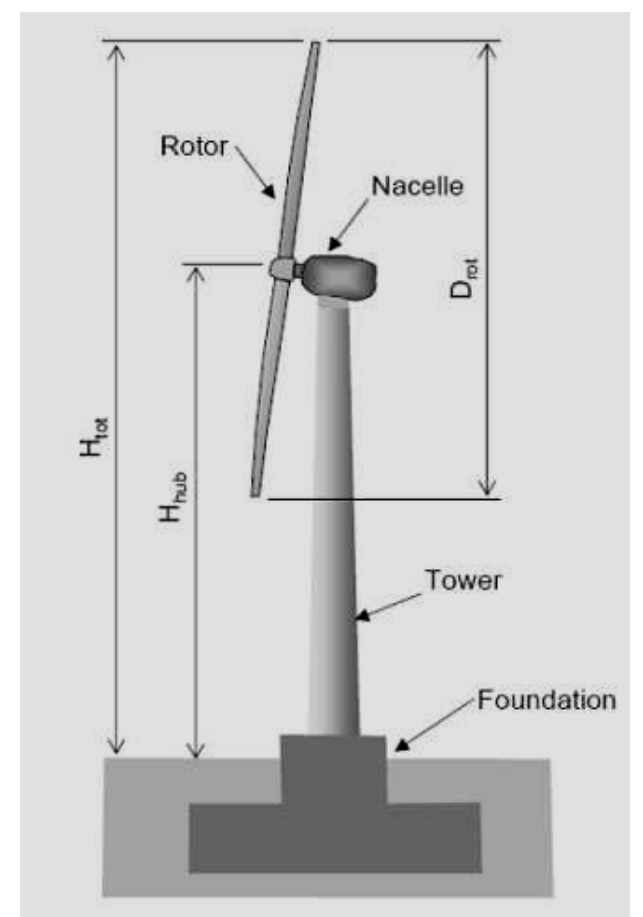

Figure 1b. The schematics of the connection of the steel tower with the concrete foundation.

There is a variety of detailing that the construction industry deals with this issue of connecting the steel tower of a wind turbine with the concrete foundation (Figures $2 a$ and $2 b$ ). The main aim of the present study is, on the one hand, to understand the operation of a wind turbine and, on the other hand, the quantification of the forces transmitted from the blades of a wide turbine to the vertical pillar which supports them. The next main objective is to study the static and dynamic behaviour of wind turbine/pylon/foundation for critical load combinations. As described above, the main region of interest is the connection of the steel tower to the foundation and the foundation itself. Towards this objective the following steps are followed: 
- Initially, the main parameters that affect the Thrust and the Torque of a horizontal axis wind turbine with rotating blades are being presented. These Thrust and Torque are then transmitted to the vertical pylon.

- Next, a software program is developed in order to calculate the magnitude of the Thrust and Torque that are transmitted from the blades to the vertical steel tower. This software is based on a relatively simplified theory and small number of parameters, including the geometry of the blades of the turbine and the flow of the wind. This is combined with the utilization of a commercial software that supports numerous parameters for the same purpose, i.e. the calculation of Thrust and Torque transmitted from the blades to the vertical steel tower. The results of the in-house simplified software are compared are compared with the outcome of the commercial software.

Finally, using the outcome of the previous step the loads to be applied on a wind turbine during the various operating conditions, as specified by relevant design provisions, were combined with design seismic scenario. For these load combinations the dynamic and seismic behaviour of an 87.6 steel tower based on a concrete foundation was investigated employing 3 -D linear elastic numerical simulations. The results of these numerical simulations is presented and discussed here.

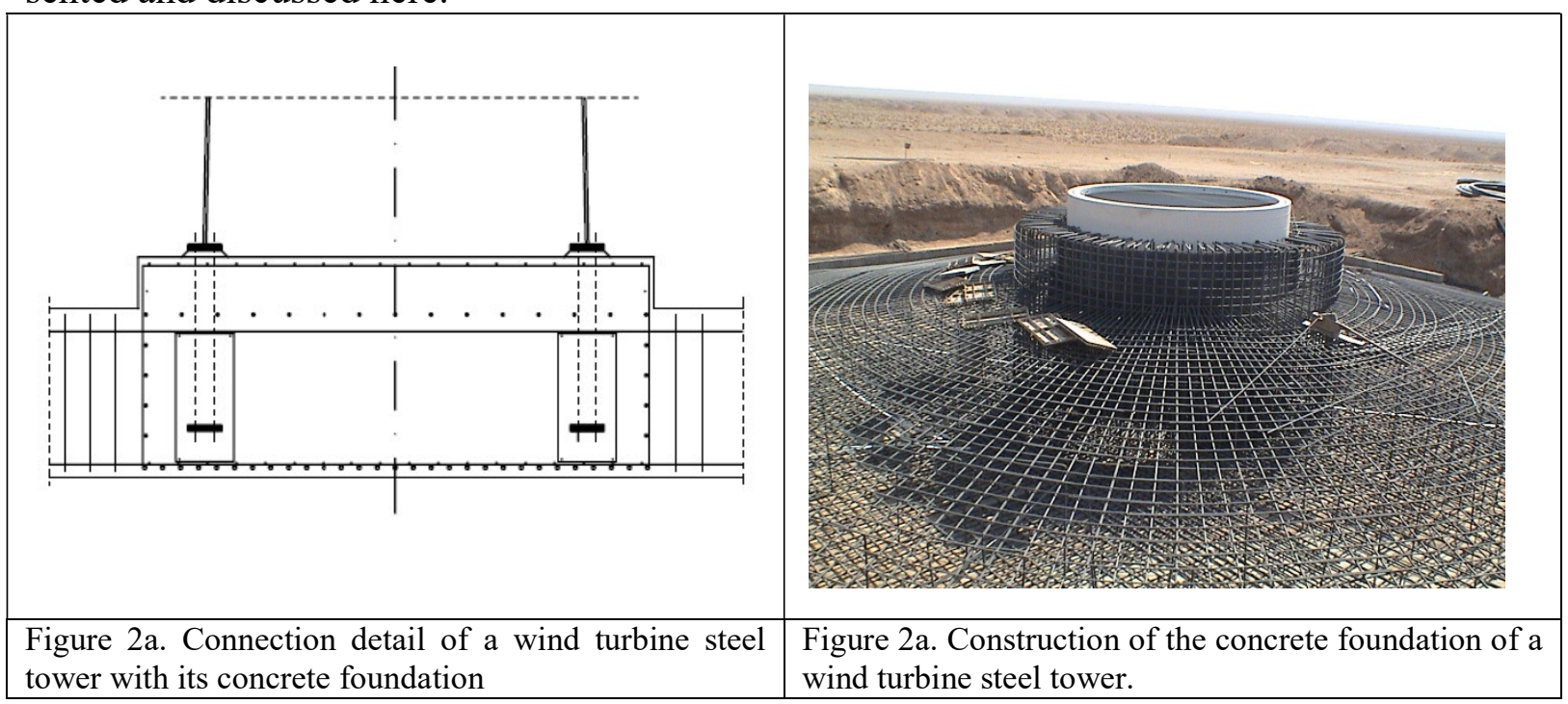

\section{LOADING CONDITIONS}

In order to define the forces transmitted by the wind turbine to the steel tower use was made two different approaches were followed. The first was a simplified approach that is based on the blade theory ([3], [5]. Each blade of a wind turbine is divided in a number of chords (i) located at a distance $\left(\mathrm{r}_{\mathrm{i}}\right)$ from the axis of the rotor of the wind turbine (figure 3 ).

For each chord the lift force $\left(\mathrm{L}_{\mathrm{i}}\right)$ and the drag force $\left(D_{i}\right)$ are calculated for a given wind velocity and a given rotational speed of the rotor of the wind turbine. The sum of the lift and drag forces for each blade of a wind turbine results in the rotor thrust and the rotor torque. These are the resultant forces transmitted through the connection of the wind turbine rotor to the steel tower.

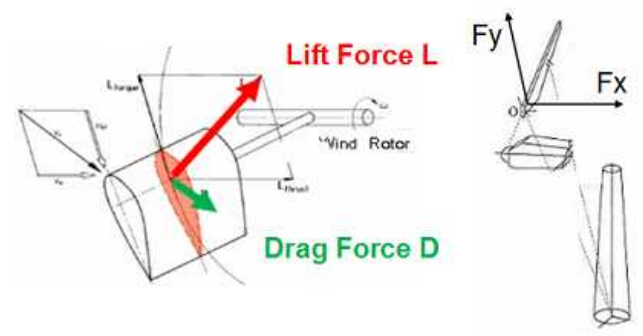

Figure 3. Lift and drag forces at a chord. 
In obtaining these generalized forces through the first approach an in-house software was developed. The second approach in obtaining the thrust and torque transmitted from the rotor of a wind turbine to the steel tower is through a specialized software (FAST $[6,7,8,9,10]$ ). This software requires a large the input information for the characteristics of the wind as well as those of the wind turbine. In the framework of the present study it was applied for an onshore NREL $5 \mathrm{MW}$ wind turbine that all the required information was available. Figure 4a depicts the time history of the rotor thrust for a wind velocity equal to $10 \mathrm{~m} / \mathrm{sec}$ and a rotor revolutionary speed equal to $12.1 \mathrm{rpm}$. Figure $4 \mathrm{~b}$ presents a comparison between the rotor thrust obtained by FAST and that obtained by the in-house software for wind velocity $13.4 \mathrm{~m} / \mathrm{sec}$ and rotor revolutionary sped $12.1 \mathrm{rpm}$.

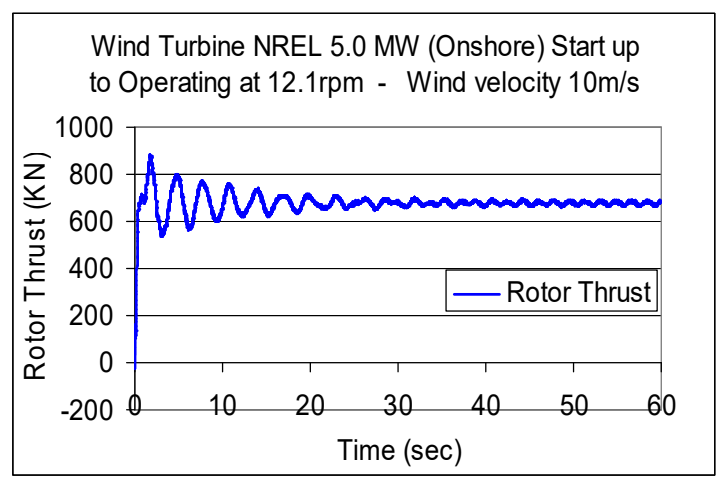

Figure 4a Rotor Thrust (FAST)

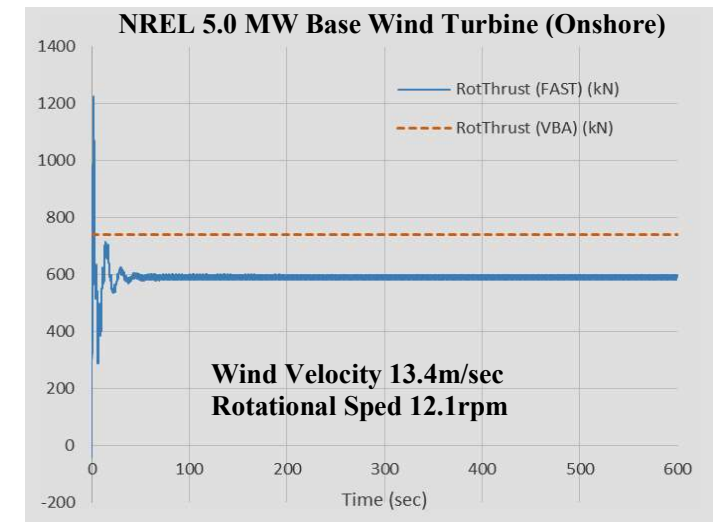

Figure $4 \mathrm{~b}$ Comparison of Rotor Trust obtained by FAST and by the in-house software

Next, for the NREL 5.0 MW Base Wind Turbine (Onshore) $[6,7,8,9,10]$ the following loading scenario were also examined. They include various cases of power production as well as cases of start up and shutdown (Start up wind velocity Vin $=3 \mathrm{~m} / \mathrm{s}$ maximum operating wind velocity Vout $=25 \mathrm{~m} / \mathrm{s}$ ). All the cases that were considered are listed in Table 1. Each case inn this table is denoted with a code name, e.g. LC 5.1 for the emergency shutdown, which will be followed throughout this manuscript. For each one of the considered scenario of table 1 the rotor thrust and torque were obtained by FAST software. They are depicted in figure 5 . The maximum and minimum values for the rotor thrust and torque for all time histories depicted in figure 5, as resulted from the FAST software, are listed in table 2. Use of these maximum and minimum values was made in the subsequent numerical analysis of the steel tower and the concrete foundation of the examined wind turbine.

\begin{tabular}{|c|c|c|}
\hline A/A & Load Case & Design Situation \\
\hline 1 & LC 1.1 & Power Production \\
\hline 2 & LC 2.1 & $\begin{array}{c}\text { Power Production + fault in the } \\
\text { control system }\end{array}$ \\
\hline 3 & LC 3.1 & Start up \\
\hline 4 & LC 3.2 & Start up \\
\hline 5 & LC 3.3 & Start up \\
\hline 6 & LC 4.2 & Normal Shutdown \\
\hline 7 & LC 5.1 & Emergency Shutdown \\
\hline 8 & LC 6.4 & Parked \\
\hline
\end{tabular}

Table 1. Various start up, operation and shutdown scenario for a wind turbine 

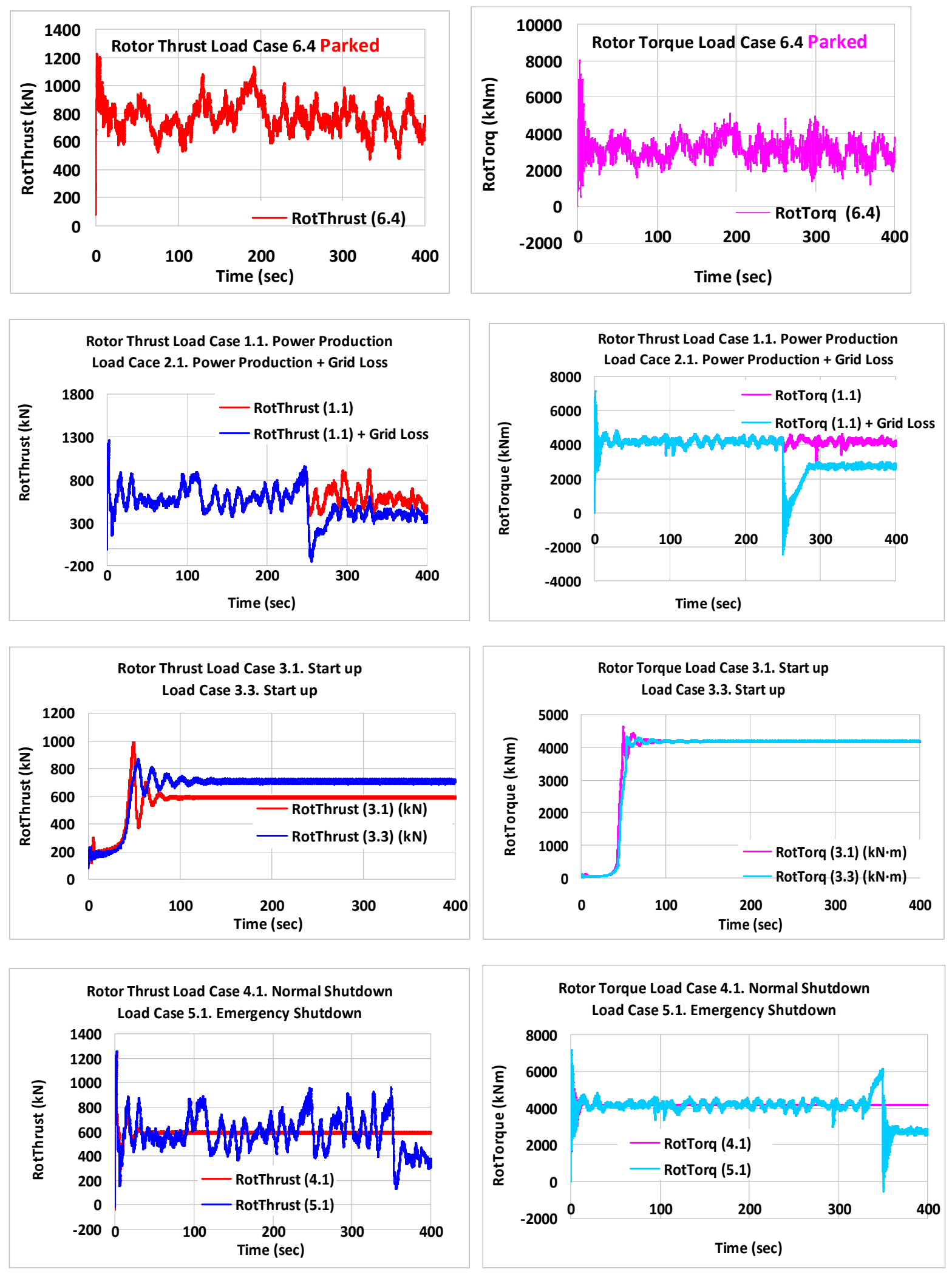

Figure 5. Rotor thrust and torque obtained by FAST for an onshore NREL $5 \mathrm{MW}$ wind turbine

As can be seen in figure 5 and table 2 the most demanding load cases in terms of rotor thrust and torque amplitudes is the emergency shutdown (LC 5.1) and the parked (LC 6.4). Figures 
6 depict basic geometric information of the steel tower and the foundation which was made use of in the subsequent numerical analysis (dimensions in meter). Finally, figure 7 depicts the design spectra (Type-1 and Type-2) based on the provisions of EuroCode-8 [11].

\begin{tabular}{|c|c|c|c|}
\hline Load Case & & Rotor Thrust $\mathbf{( k N )}$ & Rotor Torque $\mathbf{( k N m )}$ \\
\hline LC 1.1 & $\max$ & 1260 & 7157 \\
\hline \multirow{2}{*}{ LC 2.1 } & $\min$ & $-18,01$ & $-0,00025$ \\
\hline & $\max$ & 1260 & 7157 \\
\hline LC 3.1 - LC 3.2 & $\min$ & $-18,01$ & -2662 \\
\hline \multirow{2}{*}{ LC 3.3 } & $\max$ & 993,04 & 4623 \\
\hline \multirow{2}{*}{ LC 4.2 } & $\min$ & 80,84 & $-15,84$ \\
\hline & $\max$ & 871,40 & 4330 \\
\hline LC 5.1 & $\min$ & 80,84 & $-15,99$ \\
\hline & $\max$ & 1225 & 6913 \\
\hline LC 6.4 & $\min$ & $-45,54$ & -2263 \\
\hline & $\max$ & 1260 & 7157 \\
\hline & $\min$ & $-168,90$ & $-691,80$ \\
\hline & $\max$ & 1227 & 8015 \\
\hline
\end{tabular}

Table 2. Maximum and minimum values of all the start up, operation and shutdown scenario for a wind turbine considered in this study.
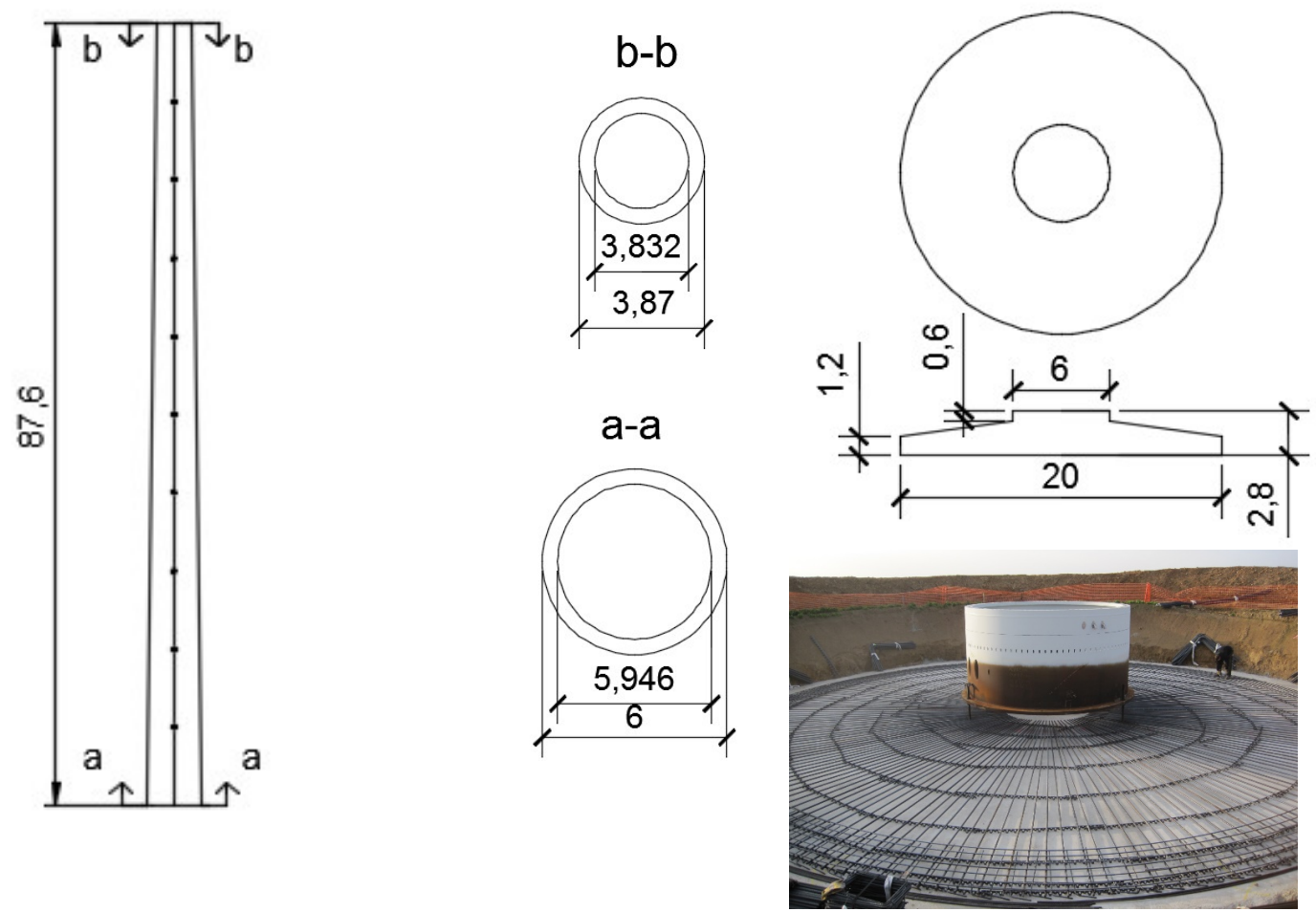

Figure 6. Basic geometry of the examined steel tower and concrete foundation of a wind turbine

These design spectra curves were derived for design ground acceleration equal to $0.36 \mathrm{~g}$ ( $\mathrm{g}$ the acceleration of gravity), which is the design acceleration for seismic zone III of Greece, representing the zone with the more intense earthquake activity. Moreover, the design spectra 
curves were also based on relatively flexible soil conditions (Soil Category D), Finally, the value for response modification coefficient (q) was set equal to 1 (representing elastic response). This was due to the fact that the steel tower is a cantilever type structural system with a considerable mass (the rotor and the blades of the wind turbine) located at the upper part of the structure

\section{Eurocode Response spectra for Seismic Zone III}

Soil $\mathrm{D}, \mathrm{ag}=0.36 \mathrm{~g} \mathrm{y}=1 \mathrm{q}=1$

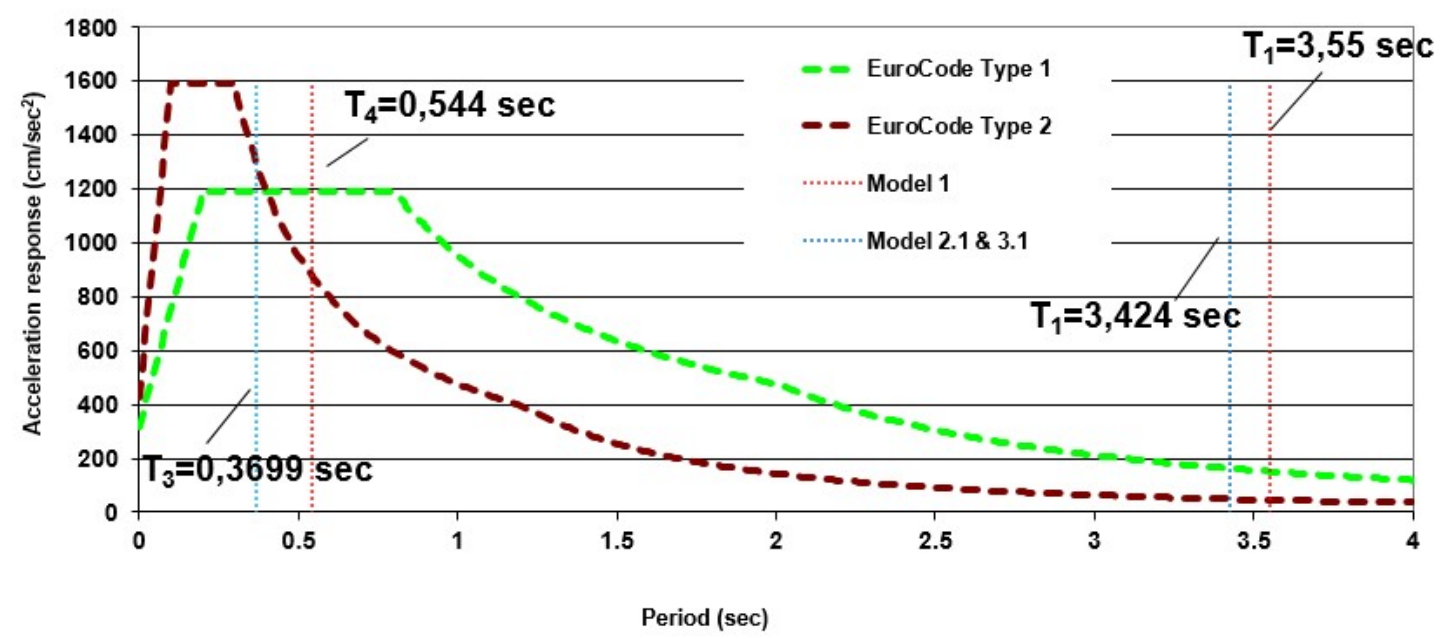

Figure 7. Design spectra based on the provisions of EuroCode- 8 .

\section{NUMERICAL ANALYSIS}

Based on the geometry of the studied wind turbine (NREL 5.0 MW Baseline Wind Turbine (Onshore) [10]), depicted in figure 6, the following numerical models were formed (figures 8 and 9).

\subsection{Numerical models}

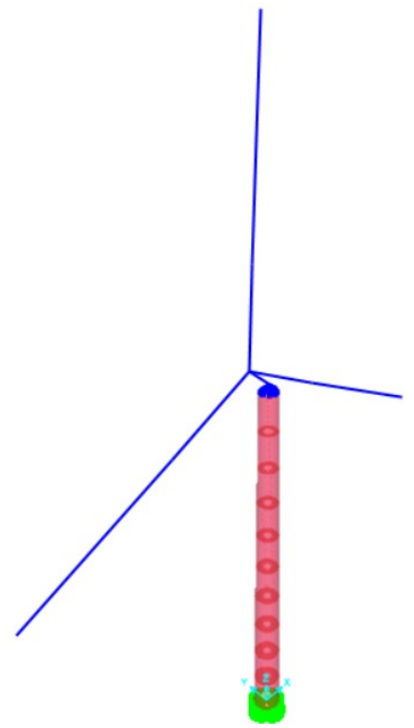

Figure 8a. Model 1.
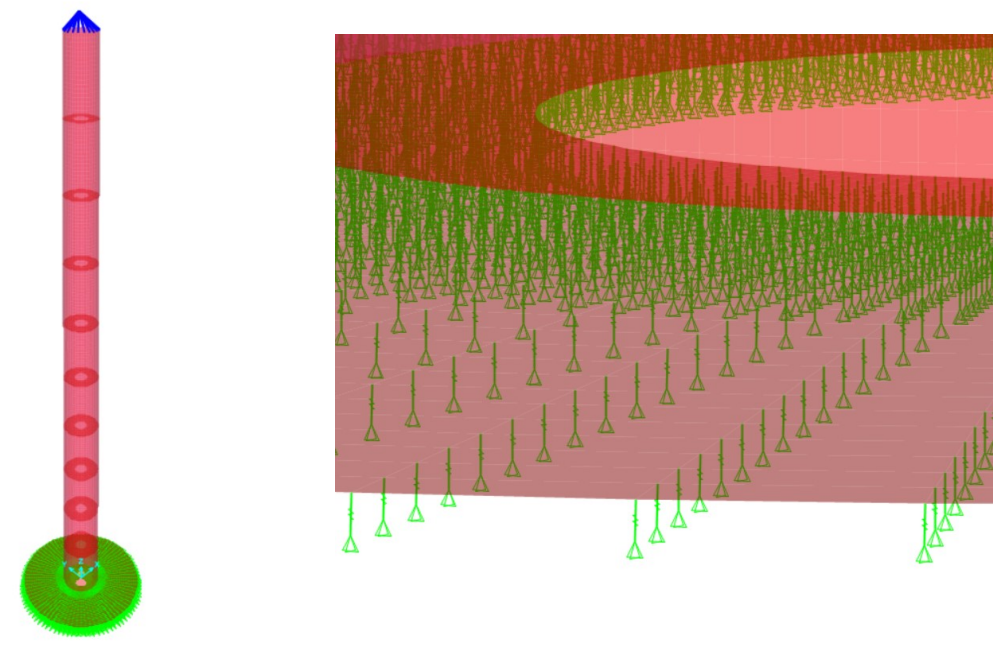

Figure 8b. Model 2.1 Figure 8c. Model 2.2 and model 2.3. 
In model 1, the steel tower with the rotor and the blades but without the foundation is numerically simulated. The steel tower is fixed at the base. In model 2.1, 2.2 and 2.3 the rotor and the blades are not simulated explicitly; instead, they are replaced by concentrated mass and mass moment of inertia, which are placed at the top of the steel tower. In this model, the foundation is also represented. Both the steel tower and the concrete foundation are represented with shell elements with the actual thickness of the various parts of either the steel tower or the concrete foundation. These shell elements were placed at the mid-surface of either the steel tower and the concrete foundation. The shell elements of the steel tower and the foundation were rigidly connected at their intersection, which was simplified as being a circular line at the base of the steel tower. In model 2.1 all the nodes of the shell elements representing the foundation were fixed (figure 8b). In models 2.2 and 2.3, all the nodes of the foundation shell elements were supported to the underlying soil medium with 3-D link elements. In model 2.2 the axial stiffness of these links elements was set to be very large $(1000 \mathrm{KN} / \mathrm{mm})$ whereas a finite stiffness value equal to $10 \mathrm{KN} / \mathrm{mm}$ was assigned to these links (Model 2.3, figure 8c). In a series of alternative numerical models (Models 3), the foundation was not directly linked to the steel tower at the base as was done for numerical models 2.1, 2.2 and 2.3. This time the foundation was extended at $1.92 \mathrm{~m}$ height from the base at the junction with the steel tower with a series of rigid frames spaced at equal intervals. There are eighty (80) such rigid frame placed in two co-centric circles with forty rigid frames at each circle, as depicted in figure 9a. The steel tower is placed within the frames of these two cocentric circles as shown in figure $9 \mathrm{~b}$. The connection between the steel tower and the foundation is accomplished by connecting the steel tower with these rigid frames through only a series of 3-D links spaced at equal intervals along the height of the rigid frames (figure $9 \mathrm{~b}$ ). The orientation of these links is horizontal. The stiffness of these links is initially very large in all three directions (model 3.1, with the foundation links being also rigid). Next, the axial stiffness (connecting the steel frame to the foundation through the rigid frames) is given a finite value equal to $10 \mathrm{KN} / \mathrm{mm}$. In this way a flexible connection between the foundation and the steel tower is introduced.

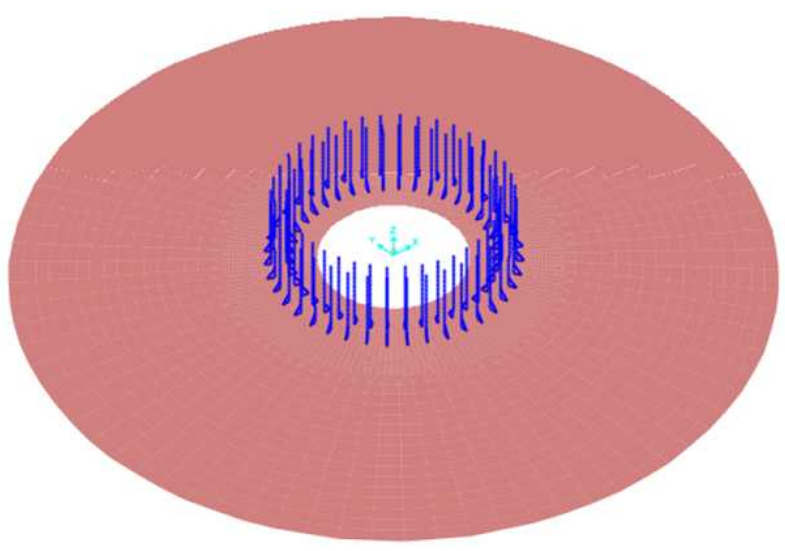

Figure 9a. Foundation of Models 3.

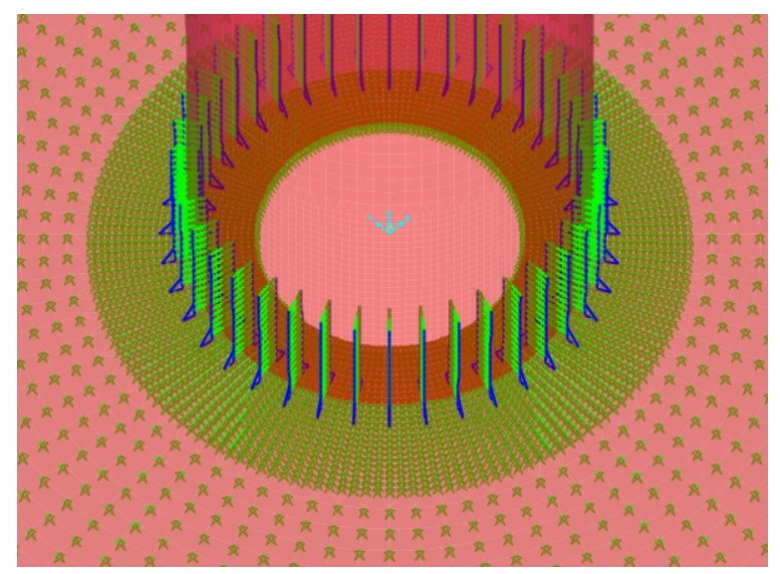

Figure 9b. Foundation of Models 3.

\subsection{Eigen-frequency analysis}

Initially, an eigen-frequency analysis was performed by employing all the previously described numerical models (models 1,2 and 3). The results are depicted in figures 10a and 10b for model 1 and in figures $11 \mathrm{a}$ and $11 \mathrm{~b}$ for models 2 and 3 . In these figures the eigen-period 
values $\left(\mathbf{T}_{\mathrm{ux}}, \mathbf{T}_{\mathrm{uy}}\right)$ in two orthogonal directions $\mathrm{x}-\mathrm{x}$ and $\mathrm{y}-\mathrm{y}$ are listed together with the corresponding modal mass participation ratio values $\left(\mathbf{m}_{\mathrm{ux}} \mathbf{m}_{\mathrm{uy}}\right)$. In figures $10 \mathrm{a}$ and $11 \mathrm{a}$ the $1^{\text {st }}$ translational eigen-modes ( $\mathrm{x}-\mathrm{x}$ and $\mathrm{y}-\mathrm{y})$ are shown whereas in figures $10 \mathrm{~b}$ and $11 \mathrm{~b}$ the $2^{\text {nd }}$ translational eigen-modes ( $\mathrm{x}-\mathrm{x}$ and $\mathrm{y}-\mathrm{y})$ are depited.
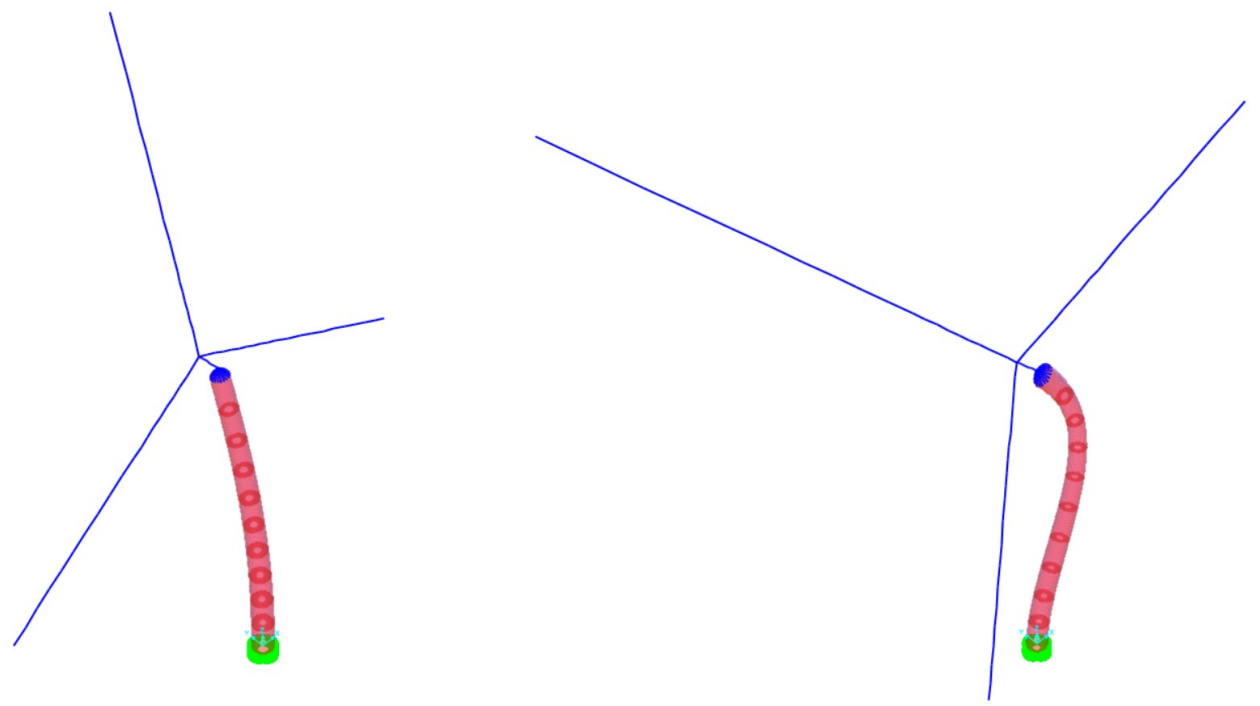

Figure 10a. Model 1, $1^{\text {st }} \mathrm{x}-\mathrm{x}$ and y-y Translational modes Figure 10a. Model 1, $2^{\text {nd }} \mathrm{x}-\mathrm{x}$ and $\mathrm{y}-\mathrm{y}$ Translational modes $T_{u x 1}=3.55 \sec m_{u x}=69.95 \%, T_{u y 1}=3.53 \sec m_{u y}=70.57 \% \quad T_{u x 2}=0.544 s e c m_{u x}=9.81 \%, T_{u y 2}=0.475 \mathrm{sec} m_{u y}=11.38 \%$

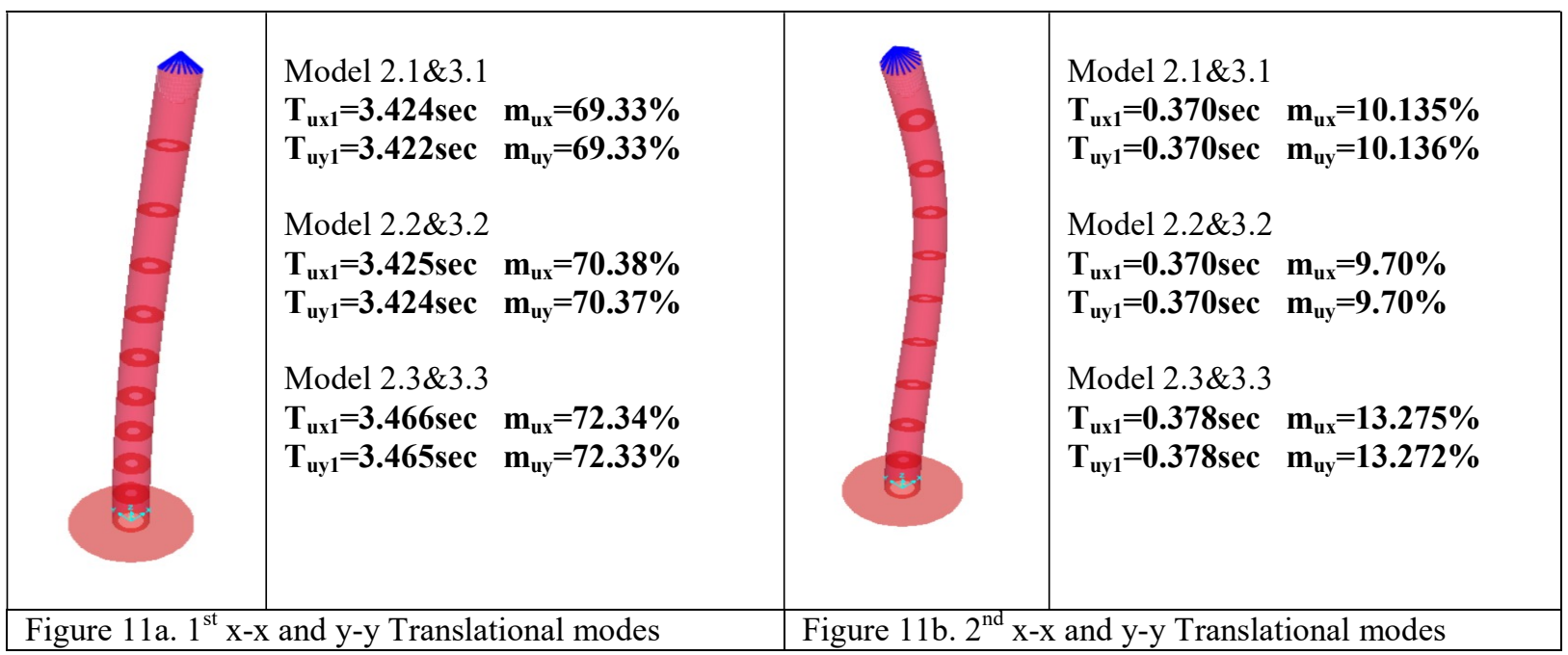

Due to the symmetry of the studied structure along the horizontal axes ( $\mathrm{x}-\mathrm{x}$ or $\mathrm{y}-\mathrm{y})$ the $1^{\text {st }}$ and $2^{\text {nd }}$ eigen-modes and eigen periods along those two horizontal exes are very similar to each other. Moreover, the introduction of flexibility at the foundation-soil interface or/and at the steel tower foundation interconnection introduces little differences in the values of the relevant eigen-periods and the corresponding modal mass participation ratios. These eigen-period values have been plotted in figure 7 in order to see the relevance of these eigen-period values with the used in this study design-spectra. 


\subsection{Numerical Results}

Summary results will presented and discussed in this section as they were obtained from the various numerical models presented in section 3.1. Moreover, the presented results are selected from those load cases (see section 2 and tables 1 and 2) that the wind turbine response is reaching limit (maximum or minimum) values. In figure 12 the maximum values at the top of the steel tower are plotted, as obtained from the various numerical models. At the left part of this figure the wind turbine normal operation (Wpprod) is combined with the dead load $(\mathrm{G})$ together with the extreme seismic loads $(0.3 \mathrm{Ex} 1+\mathrm{Ey} 1)$. At the right part of the same figure, the parked wind turbine (1.35Wparked) is combined with the dead load $(0.90 \mathrm{G})$. As can be seen the later combination results in larger values $(1.2 \mathrm{~m})$ of horizontal displacements at the top of the steel tower than for the former load combination
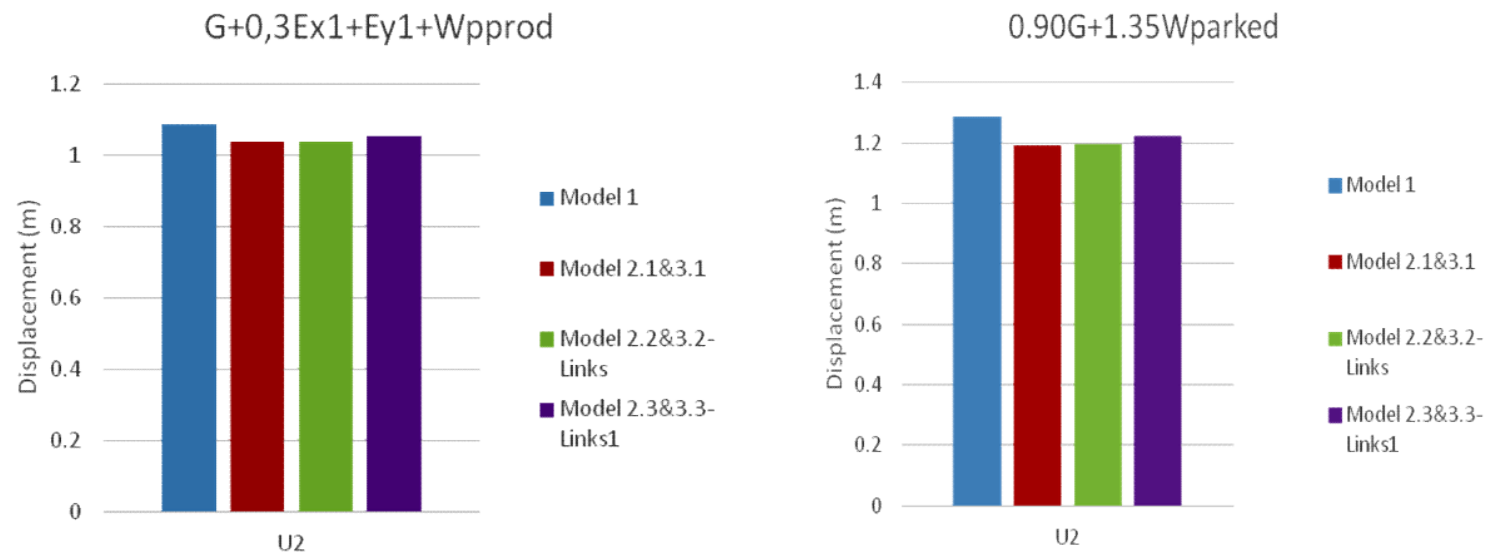

Figure 12. Maximum horizontal displacements at the top of the steel tower

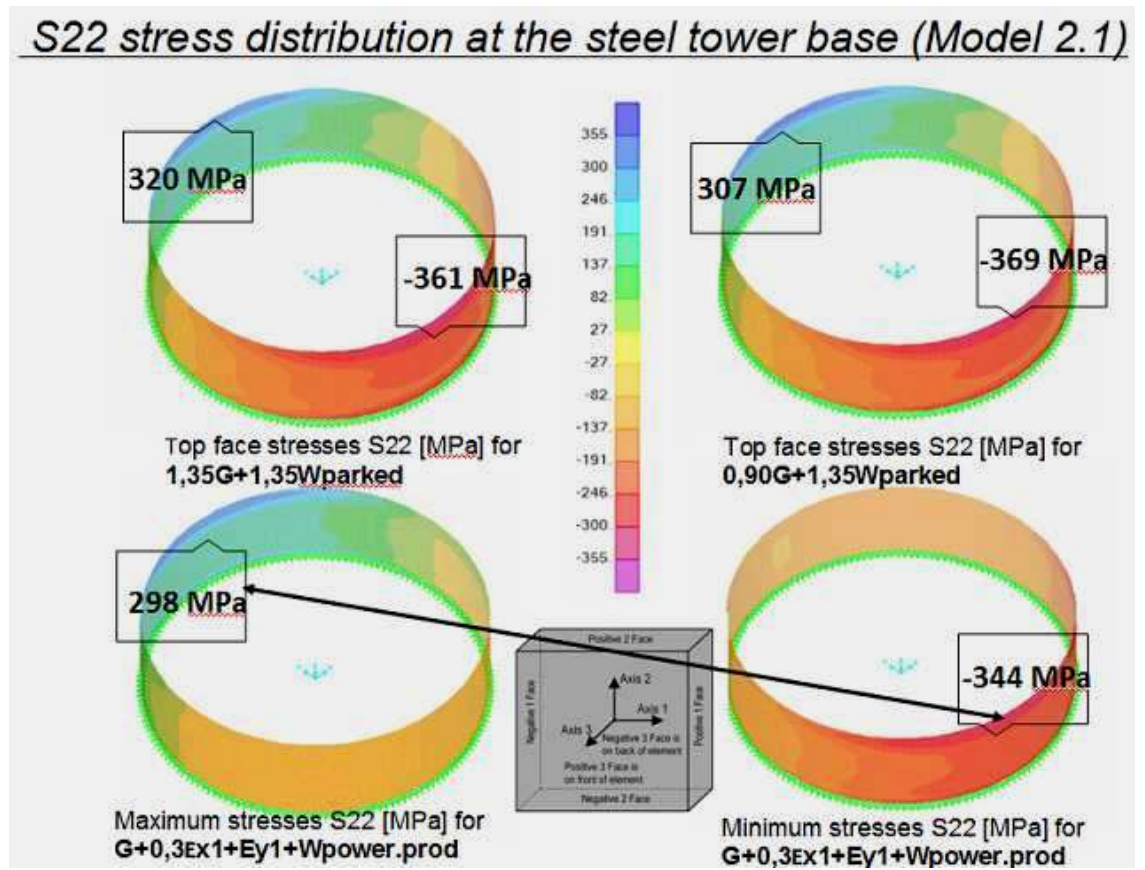

Figure 13. Axial S22 stress distribution at the base of the steel tower

In figure 13 the axial S22 stresses near the base of the steel tower are plotted as they are distributed around the base circumfarance. This distribution is plotted for four different load cases; that is a) $1.35 \mathrm{G}+1.35 \mathrm{~W}$ parked, b) $0.90 \mathrm{G}+1.35$ Wparked, c) $\mathrm{G}+0.3 \mathrm{Ex} 1+\mathrm{Ey} 1+\mathrm{W}$ pprod (Maximum) and d) G+0.3Ex1+Ey1+Wpprod (Minimum). As can be seen in this figure, load 
cases a) $1.35 \mathrm{G}+1.35 \mathrm{~W}$ parked, b) $0.90 \mathrm{G}+1.35 \mathrm{~W}$ parked result in the maximum axial tensile $(320 \mathrm{MPa})$ and in the minimum axial compressive stress (-369) value.

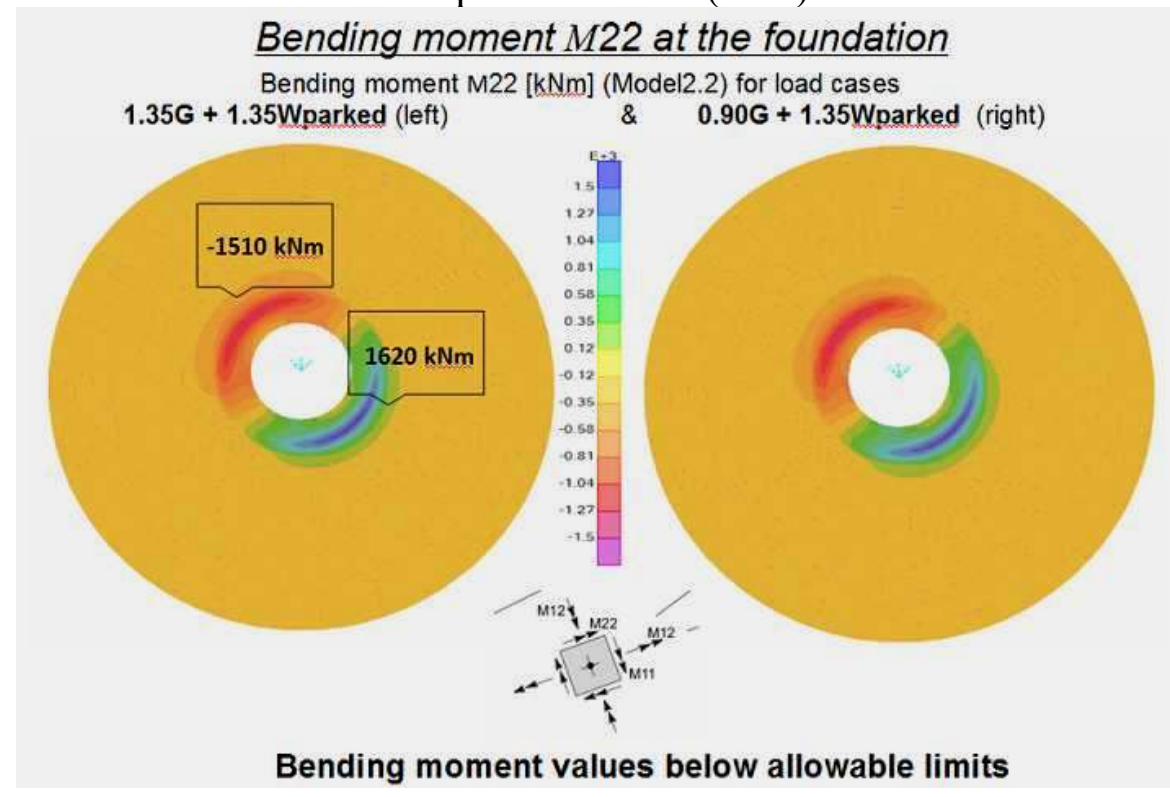

Figure 14. Distribution of bending moments near the intersection of the steel tower with the concrete foundation. Rigid foundation-soil interface (Model 2.2)

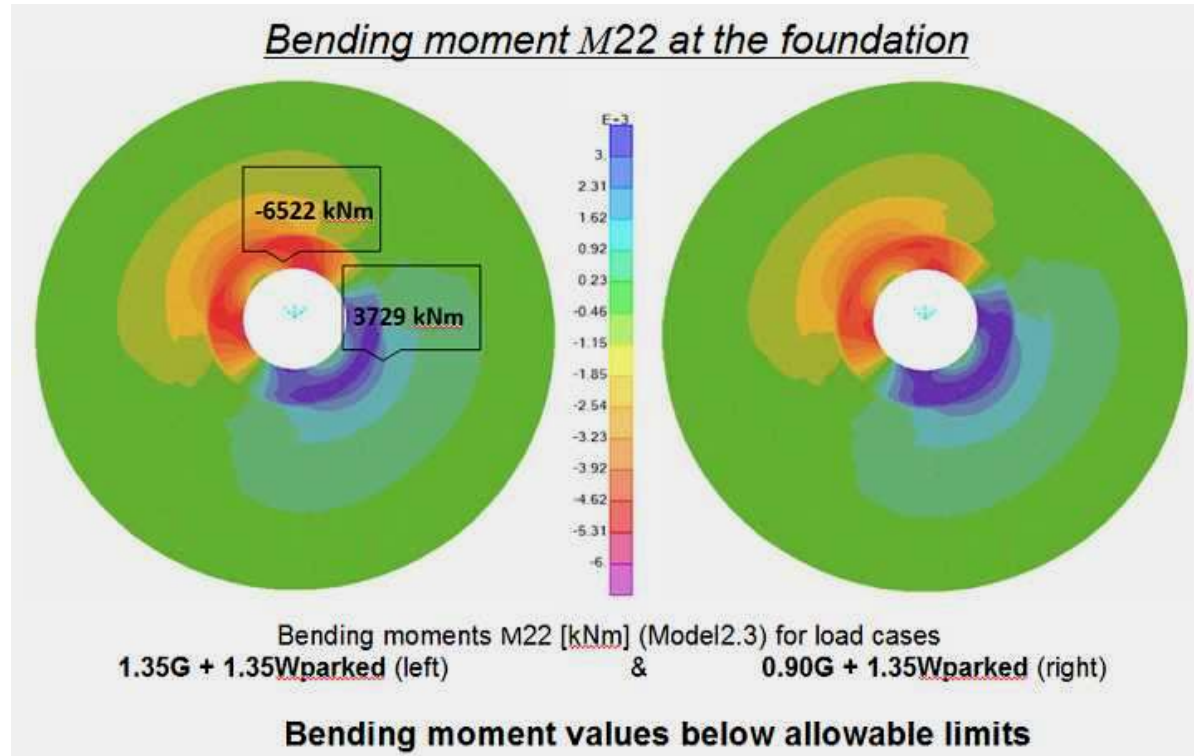

Figure 15. Distribution of bending moments near the intersection of the steel tower with the concrete foundation. Flexible foundation-soil interface (Model 2.3)

In figure 14 the distribution of the bending moment M22 are plotted as they were obtained from numerical model 2.2 (rigid foundation interface). Again this distribution is obtained for load combinations a) $1.35 \mathrm{G}+1.35 \mathrm{~W}$ parked and b) $0.90 \mathrm{G}+1.35 \mathrm{~W}$ parked and they represent bending moment values that develop at the intersection of the steel tower with the concrete foundation. As can be seen in these plots, the maximum and negative bending moment value is $1620 \mathrm{KNm}$ and $-1510 \mathrm{KNm}$, respectively, which is below the allowable limit. The distribution of the bending moment M22 is plotted again in figure 15. This time, however, a flexibility is introduced at the interface between the concrete foundation and the soil, as described in section 3.1. As can be seen by comparing the obtained limit bending moment values in figure 
15 and 14, this flexibility resulted in a significant increase in the value of the bending moment for the concrete foundation near the intersection with the steel tower. This time, the maximum and negative bending moment value is $3729 \mathrm{KNm}$ and $-6522 \mathrm{KNm}$, respectively, which is beyond the allowable limit.

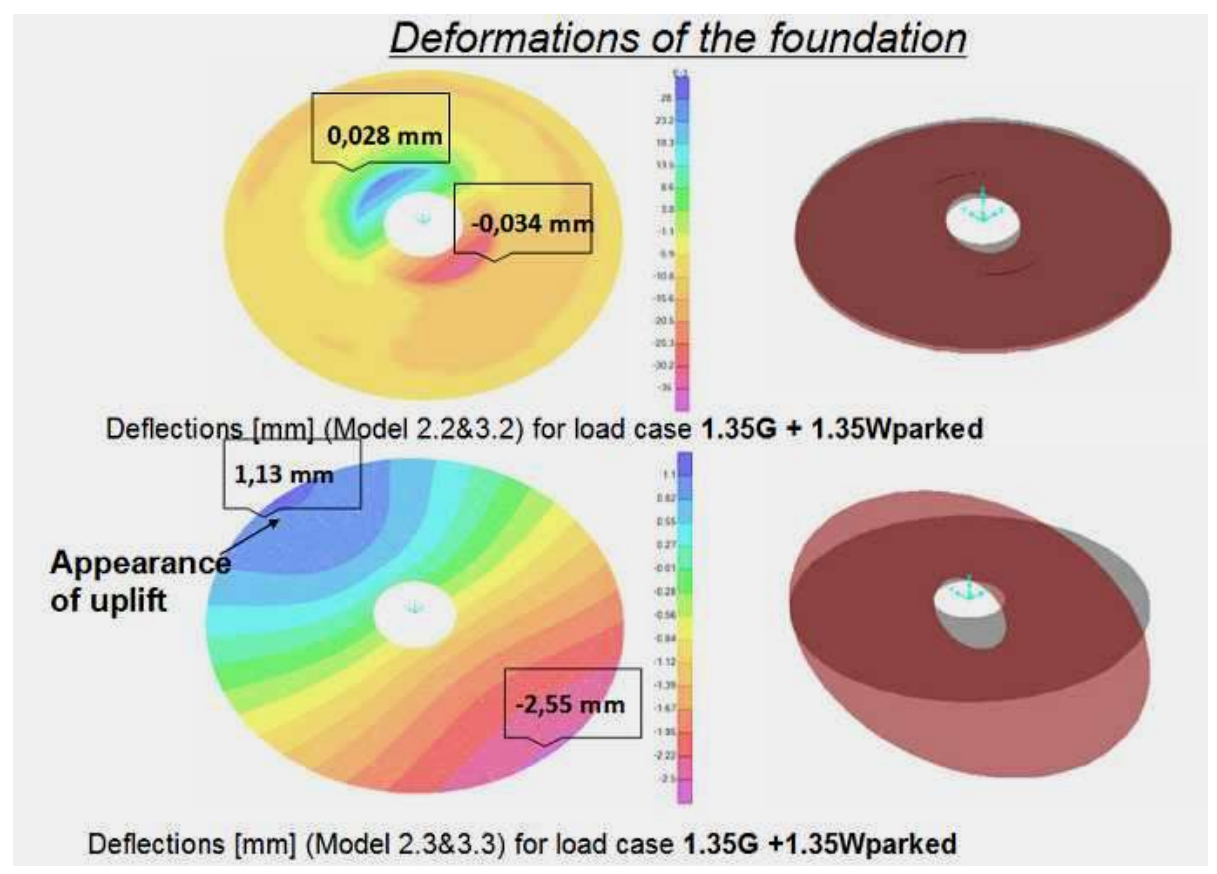

Figure 16. Deflection of the foundation

In figure 16 the deflections that develop at the foundation are plotted, as they were obtained for numerical models with a rigid foundation-soil interface (models 2.2 and 3.2) or with a flexible interface (models 2.3 and 3.3). These concrete foundation deflections were derived by considering the load case $1.35 \mathrm{G}+1.35$ Wparked. In the upper part of figure 16 the deflections that are plotted represent the rigid interface where at the bottom of the same figure the deflections are for the flexible interface. As can be seen from this comparison, the introduced flexibility results in much larger values for the obtained deflections that lead part of the foundation to tend to uplift in the top left hand side of its periphery by $1.13 \mathrm{~mm}$.

\section{CONCLUSIONS}

1. The main objective of this work is to study the static and dynamic behaviour of wind turbine/pylon/foundation for critical load combinations. The main region of interest is the connection of the steel tower to the foundation and the foundation itself.

2. A software program is developed in order to calculate the magnitude of the Thrust and Torque that are transmitted from the blades to the vertical steel tower. This software is based on a relatively simplified theory and small number of parameters, including the geometry of the blades of the turbine and the flow of the wind. This is combined with the utilization of commercial software that supports numerous parameters for the calculation of Thrust and Torque transmitted from the blades to the vertical steel tower. The results of the in-house simplified software are in reasonable good agreement compared with the outcome of the commercial software. 
3. A variety of numerical models were formed in order to investigate the influence of the flexibility of the interface between the concrete foundation and the soil as well as the flexibility of the intersection of the steel tower with the concrete foundation. The introduction of flexibility at the foundation-soil interface or/and at the steel tower foundation interconnection introduces little differences in the values of the relevant eigenperiods and the corresponding modal mass participation ratios.

4. The load combination that includes $90 \%$ of the gravity forces together with $135 \%$ of the forces produced by the wind when the wind turbine is parked results in the largest values $(1.2 \mathrm{~m})$ of horizontal displacements at the top of the steel tower. Again the load combination of the gravity forces with the wind power when the wind turbine is parked results in the largest (compressive and tensile) axial stress values at the base of the steel tower.

5. Introducing a flexible interface between the concrete foundation and the underlying soil results in considerable increase of the bending moment values near the interesection of the steel tower with the foundation that are larger than the relevant allowable limit. Moreover, this flexibility also results in a considerable increase in the values of the deflection of the concrete foundation that leads part of this foundation to tend to uplift at its periphery.

\section{REFERENCES}

[1] M. Buhl, J. Jonkman (March 2007). "IEC Wind”, NREL, National Renewable Energy Laboratory.Golden, CO.

[2] Burton T, Sharpe S, Jenkins N and Bossanyi E (2001) Wind Energy Handbook. Wiley, Chichester, UK, pp. 211-219.

[3] Martin O. L. Hansen. Aerodynamics of Wind Turbines. 2nd ed. Earthscan,2008.

[4] Søren Gundtoft. Wind Turbines. University College of Aarhus. June 2009

[5] Grant Ingram. Wind Turbine Blade Analysis using the Blade Element Momentum Method. Version 1. October 18, 2011

[6] International standard IEC61400-1 third edition.Wind Turbines-Part1-Design Requirements. 2005

[7] Jonkman, B. J., and Buhl Jr., M. L. (2007). “TurbSim User's Guide," Tech. Rep. NREL/TP-500-41136, National Renewable Energy Laboratory, Golden, CO.

[8] J. Jonkman, S. Butterfield, W. Musial, and G. Scott.Definition of a 5-MW Reference Wind Turbine for Offshore System Development.Technical Report NREL/TP-50038060.February 2009

[9] Jonkman J. M. and Buhl Jr., M. L. (2005). FAST User's Guide. NREL/EL-500-38230 (previously NREL/EL-500-29798). Golden.CO: National Renewable Energy Laboratory. August 2005 . 
[10] Bonnie Jonkman and Jason Jonkman. "FAST v8.10.”,NREL, , National Renewable Energy Laboratory.Golden, CO. March 2015

[11] Eurocode 8: EN 1998-1: Design of structures for earthquake resistance - Part 1: General rules, seismic actions and rules for buildings, Brussels, 2004.

[12] SAP2000 version 18, CSI Analysis Reference Manual, Computers and Structures, INC,Structural and earthquake engineering software

[13] Henrik Svesson, 2010 , Design of foundations for wind turbines.

[14] David A. Spera Wind Turbine Technology Fundamental Concepts of Wind turbine engineering second edition.2009 